\title{
ANÁLISIS DE RESULTADOS DE LAS POLÍTICAS DE DESARROLLO RURAL. LAS COMARCAS LEADER DE SEVILLA
}

Eva BUITRAGO ESQUINAS*

Concepción FORONDA ROBLES**

\section{INTRODUCCIÓN}

La evolución histórica de las estructuras productivas en el medio rural, bajo el proceso de desarrollo capitalista, ha supuesto un problema para separar el mercado de trabajo agrario del ruraI. A partir de la revolución verde y de la introducción de las nuevas técnicas se produce una intensificación de las formas capitalistas en el sector agrario que incide negativamente en el mercado de trabajo al acentuar la estacionalidad y la precariedad del empleo. La crisis industrial se suma a estos procesos, dando lugar a importantes excedentes de fuerza de trabajo en las zonas rurales. Frente a los conflictos generados entre el sistema capitalista y el libre juego del mercado de trabajo se utilizan políticas represivas y asistenciales, vislumbrándose la funcionalidad de estas últimas para la pervivencia del sistema.

La estrategia de la Unión Europea, fundamentalmente la reforma de la Política Agraria Comunitaria (PAC) y el Mercado Único, plantea una política menos productivista y más cuidadosa con el entorno para fijar la población al medio ruraI y evitar los excedentes. Esto ha supuesto una serie de importantes cambios en el tejido productivo, no suficientemente valorados, ya que las estrategias de los poderes públicos españoles y europeos, según Martín (1996), están pasando de la actividad agraria a la potenciación de la conservación y del disfrute del ocio.

Por este motivo, han surgido iniciativas comunitarias basadas en un enfoque local que persiguen la estimulación y creación de actividades complementarias. La iniciativa LEADER I supuso el primer intento de implantar este nuevo concepto de desarrollo rural, la cual se ha continuado con la iniciativa LEADER II y la

* Dpto. Economía Aplicada III. Universidad de Sevilla.

** Dpto. Geografía Humana. Universidad de Sevilla. 
aprobación del Programa de Desarrollo y Diversificación Económica en la Zonas Rurales (PRODER).

La multiciplidad de componentes que constituye la esencia del medio rural h sufrido en los últimos años, una serie de modificaciones profundas que, de una otra forma, son responsables de la situación actual. Estos cambios, en alguna ocasiones, son factores desencadenantes de un problema, pero en otras situacio nes significan una posible oportunidad que, adecuadamente aprovechada, pued redundar en el desarrollo de estas zonas. Los estrangulamientos estructurales má importantes son:

a) La debilidad demográfica, que se manifiesta fundamentalmente a través di la baja densidad de población y del envejecimiento.

b) La difícil y limitada accesibilidad debido a la escasa dotación de infraes tructuras de transportes, telecomunicaciones, etc.

c) El déficit comparativo de equipamiento, sobre todo en materia de sanidad educación, vivienda y otros servicios públicos.

d) La escasa formación y cualificación de la mano de obra, cuando hoy es alg، generalmente admitido que el capital humano juega un papel clave en to dos los procesos de desarrollo.

Nos encontramos ante un circulo vicioso, cuya solución implica costes econó micos relativamente más elevados, debido al menor número de usuarios, la leja nía, las características geográficas y otras causas.

En los últimos años se ha despertado un gran interés por conocer las pautas dt crecimiento económico de las regiones. Son numerosos los trabajos publicados, cor datos muy fragmentarios y de naturaleza básicamente demográfica y fiscal, qut tratan de aproximarse a ofrecer una explicación sobre posibles tendencias históri cas de localización de las actividades económicas, pretendiendo identificar su: respectivos patrones de crecimiento y diseñar políticas económicas ajustadas a sus propias peculiaridades.

El objeto de esta ponencia es demostrar el cumplimiento de los objetivos dt las políticas de desarrollo rural en las comarcas LEADER. Para ello, primerc conceptualizamos el desarrollo rural y analizamos las políticas que se están lle. vando a cabo en dicho sentido, para recopilar los principales objetivos que éstas consideran. Establecidos los objetivos teóricos, se comprueba la situación real d $\epsilon$ las comarcas sevillanas, empleando variables de crecimiento y desarrollo.

Desde la óptica del crecimiento, nos centramos en el análisis de la renta parć comprobar el incremento de la actividad económica y su diversificación.

Desde la óptica del desarrollo, analizamos variables demográficas, del merca. do de trabajo, y de los servicios sanitarios, educativos y culturales para constata1 la existencia de la mejora del nivel de vida de la población rural. 


\section{POLÍTICAS DE DESARROLLO RURAL}

Entre los diferentes autores que han tratado las dificultades del medio rural, en los países desarrollados, la Comisión Europea fue precursora con la elaboración en 1988 del informe "Las perspectivas sobre la Política Agraria Comunitaria», conocido como Libro Verde. En él, el desarrollo agrario va a ser sustituido por el desarrollo rural y la mejora de las rentas agrarias por la potenciación de la pluriactividad-pluringresos.

Más tarde, con «El futuro del mundo rural» (COM (88) 505), se perfila aún con mayor claridad la opción de un desarrollo del mundo rural no basado en la actividad agraria. La principal razón que llevó a elaborar tal documento fue la convicción de que el modelo de política agraria común seguido hasta el momento estaba agotado y que no se justificaban ya sus objetivos en un contexto de fuertes excedentes estructurales, grave deterioro del medio ambiente, fuerte gasto agrario y perturbación de los mercados internacionales por efecto de las restituciones enropeas. Desde entonces, se ha venido pensando que la necesaria reforma de la PAC iba a generar una crisis agraria a la que convenía anticiparse apuntando posibles cambios y soluciones:

1. Frente a las presiones del mundo moderno sobre el mundo rural, la UE manifiesta que el objetivo de este espacio no está sólo en seguir el crecimiento económico de las regiones rurales sino también el incremento de la protección del medio rural y la ordenación progresiva del territorio.

2. Frente a la decadencia rural, la revitalización e integración del tejido socioeconómico supone una política de creación de empleos duraderos y económicamente viables fuera del sector agrario: apoyar el turismo, la artesanía, pyme y actividades forestales.

3. Frente a los problemas de las zonas marginadas será necesario mantener a la población rural, así como la conservación del entorno natural y patrimonio cultural.

Lo más importante de este documento es que acaba definitivamente con el enfoque sectorial, sustituyéndolo por el enfoque local del desarrollo rural, lo que representa un cambio de actitud muy importante (Requena, 1996). Hasta este documento no existían verdaderas estrategias nacionales o comunitarias de desarrollo en las zonas rurales.

A partir de ese momento, el desarrollo rural empieza a ser considerado como una necesidad social y política, pero el principal problema es qne no dispone de un cuerpo doctrinal sobre el que montar posibles políticas futuras. Éste se concibe como una motivación económica y una ordenación del espacio rural a escala 
local, a través de la delimitación y coordinación de objetivos integrados tales com inversiones, mejoras que incrementen las rentas y calidad de vida de los habitan tes, formación de recursos humanos, articulación de la vida local mediante lo: servicios mínimos, empleo, etc.

Para adaptarse a la normativa comunitaria, el Gobierno español dictó, a prin. cipios de los 80, una serie de medidas y normas como la Ley de Agricultura dє Montaña (1982). Desde el momento de la integración se produce una fuerte con. tradicción, según Tío (1995), entre las orientaciones de la política agraria españo. la, estímulo de la competitividad basada en la modernización y expansión produc. tiva, y la comunitaria, de orientación recesiva.

La Ley de Agricultura de Montaña española, a pesar de su nombre, es la pri. mera disposición que plantea la problemática de las «zonas de montaña», desde una perspectiva integral, para dar un tratamiento diferencial a estos espacios y posibilitar la ordenación y gestión de los mismos. Tiene como objeto la delimitación de unas áreas que por sus condiciones naturales de altitud o pendiente se encuentran en condiciones de desventaja para la práctica agrícola y que, a consecuencia de ello, se hallan en franco proceso regresivo en términos económicos y poblacionales.

De igual modo, la transcendencia de los problemas agrarios y rurales en Andalucía justifica que, en 1993, se redacte el documento de partida «Bases para un Plan de Desarrollo Rural Andaluz» sobre los problemas de la sociedad rural. reelaborando antiguos enfoques e incorporando las nuevas ideas que sobre el mundo rural se vienen desarrollando en la Unión Europea.

El Plan de Desarrollo Rural (PDRA), cuyo propósito era articular y coordinat las políticas de actuaciones, tenía por objeto posibilitar que fuera utilizado comc instrumento al servicio del desarrollo rural. Los objetivos que se establecían eran:

a) la generación de empleo en el medio rural,

b) el aumento del nivel de renta de su población y

c) la mejora de sus condiciones de vida y de trabajo.

Para lograr dichas metas, el PDRA proponía una serie de líneas estratégicas, las cuales se están haciendo realidad a través de las iniciativas de las distintas administraciones públicas:

1. La movilización social y cultural de la sociedad está ayudando a impulsar las transformaciones del medio rural, a través de la dinamización social, la formación y cualificación profesional y la conservación del patrimonio.

2. La diversificación y modernización de las actividades económicas aprovechan al máximo los recursos infrautilizados u ociosos de cada comarca. 
3. El tercer eje de la equidad territorial, que parte de las desigualdades, es quizás el que menos se ha conseguido, en cuanto a desarrollo y bienestar entre las áreas. Las políticas de mejora de la infraestructuras rurales, la de equipamientos y servicios colectivos y las de servicios sociales están constituyendo las líneas básicas para compensar dichos desequilibrios.

Finalmente, la «Guía de Desarrollo Rural de Andalucía» (1997) ha servido como medio de información y asesoramiento a las corporaciones locales, agentes públicos y privados, interesado en la promoción y desarrollo de las áreas rurales en Andalucía.

\subsection{El uso terminológico de desarrollo rural}

El término «desarrollo rural» ha estado sometido a toda una serie de definiciones e interpretaciones a lo largo del tiempo, incluso no siempre ha tenido un contenido propio. En efecto, el desarrollo económico emerge como subdisciplina académica, en los años cincuenta, debido a la nueva visión surgida en los gobiernos tras la segunda guerra mundial (Ceña Delgado, 1993), en cambio el desarrollo rural no nacerá como campo independiente hasta la década de los setenta.

La emergencia del protagonismo del medio rural, en el conjunto de los problemas socioeconómicos de la sociedad, se debió a los resultados negativos de la experiencia de dos décadas de desarrollo económico, la cual llevó a los organismos internacionales con competencias en materia de desarrollo a plantearse nuevos enfoques. Así por ejemplo, el Banco Mundial (1975) definió el desarrollo rural como «una estrategia diseñada para mejorar el nivel de vida económico y social de grupos específicos de población». En los años ochenta se amplía este concepto como consecuencia de la nueva preocupación medioambiental de la sociedad, y lo definen como «una mejora global en el bienestar económico y social de los residentes rurales del medio físico e institucional en los que ellos viven». Ambas definiciones, no obstante, hacen hincapié en el bienestar de los que viven en el medio rural únicamente.

En los años setenta, las políticas de desarrollo rural han de ser reorientadas, estaban en boga las estrategias de Ios «Polos de Desarrollo», basadas en la teoría de la difusión del crecimiento, pero no tuvieron éxito porque esta difusión necesitaba mucho tiempo. No obstante, a pesar de estas políticas las zonas rurales han seguido su declive económico y demográfico.

Las circunstancias ya referidas y los resultados insatisfactorios de las políticas anteriores reafirman la necesidad de un enfoque de las políticas de desarrollo rural más amplio e integrado. En esta línea, la OCDE en 1987 adoptó con la elaboración de la reforma de la política agraria, que el ajuste necesario en el sector 
agrario se vería apoyado por el desarrollo de otras actividades en las áreas rurales (El futuro del mundo rural). Por tanto, la reorientacióu de las políticas de desarrollo rural puede ser vista como meras modificaciones a las políticas anteriores, tal sería el caso de la reforma de la PAC: reducir los excedentes, ayudar a los agricultores pequeños en vez a los grandes y poner énfasis en la diversificación de las actividades rurales, en especial servicios en lugar de industria.

Las estrategias que actualmente se consideran más adecuadas para resolver los problemas señalados giran en torno al concepto de desarrollo rural integrado, construida sobre la pluriactividad económica (Etxezarreta, 1988). Básicamente se refieren a la conveniencia de lograr el desarrollo rural mediante esquemas de actividad económica de base territorial, por lo que se potencia la dinamización de los recursos existentes en la misma, suponiendo no sólo el aprovechamiento de los recursos humanos sino también la utilización de los recursos disponibles para estimular todas aquellas actividades que puedan tener lugar en el medio rural. Según Tio (1995), ello permitirá la obtención de ingresos suficientes para un nivel de vida satisfecho.

Por tanto, no existe acuerdo generalizado sobre lo que estrictamente pudiera ser denominado como desarrollo local. Son muchas las experiencias e iniciativas que tienden a ser consideradas bajo esta noción: industrialización difusa; distritos industriales; iniciativas municipales, de mancomunidades o de otros entes locales de promoción o creación de actividades económicas; experiencias empresariales más o menos asalariadas o integradas. Todas ellas constituyen una lista no exhaustiva de casos de desarrollo en el ámbito local.

Para Pérez Yruela, M.; Giménez Guerrero, M. (1995), el desarrollo local consiste en volver la vista hacia recursos ociosos; hacia la recuperación de oportunidades de creación de actividades productivas realmente existentes y nunca aprovechadas, que fueron abandonadas y hoy pueden volver a ser fuente de riqueza o que languidecen cuando pueden ser potenciadas; hacia el aprovechamiento de las oportunidades que presentan las nuevas tecnologías, la reorganización de los procesos productivos, los cambios en la demanda, la mejora de las comunicaciones de todo tipo y el acceso a nuevos mercados. En segundo lugar, se trata de descubrir esas posibilidades no sólo en los lugares donde se había acumulado la experiencia empresarial y laboral, sino también en otras áreas territoriales con poca o ninguna acumulación de esos factores. En tercer lugar, consiste en tratar de identificar, estimular y apoyar a los actores capaces de llevar a cabo las actividades. En cuarto lugar, consiste en movilizar este conjunto de factores en el contexto «local», esto es, aplicando las estrategias de actuación a un ámbito de dimensión y características apropiadas para poder llevar a cabo esta movilización, a través de procesos de intervención económica y social, con ciertas garantías de viabilidad.

Existen una serie de funciones comunes a todas las Administraciones Públicas en materia de desarrollo rural: 
- Cofïnanciar programas de desarrollo a través de los distintos fondos estructurales y de cohesión.

- Crear las condiciones para reconstruir y mantener el tejido organizativo social en las áreas rurales.

- Desarrollar y mejorar las infraestructuras.

- Asegurar servicios sociales básicos y equiparables a los del resto de la sociedad en materia de educación, sanidad, transporte, telecomunicaciones, etc.

- Diuamizar el mundo rural poniendo énfasis en las zonas y sectores con poca capacidad de generar sus propios procesos de desarrollo.

- Realizar inversiones dirigidas a mejorar la competitividad de las empresas ubicadas en el medio rural.

- Desarrollar una estrategia medioambiental adecuada a cada comarca.

\subsection{EI programa LEADER}

El programa LEADER II (1994-1999) es la segunda etapa, ampliada y consolidada de la experiencia piloto LEADER I, vigente en España en el periodo 19911994. Se trata de una iniciativa comunitaria que responde a la coucepción moderna de los planteamientos del desarrollo rural.

Su finalidad central es contribuir al mantenimiento de la población en el medio rural en condiciones socioeconómicas equiparables y sostenibles, promoviendo y apoyando alternativas innovadoras de actividad rural que generen rentas y empleo, dentro del respeto del entorno y de la conservación de los recursos naturales.

Sin embargo, esta declaración de propósitos no pasa de ser una expresión genérica que requiere la caracterización del programa para obtener la verdadera identidad del LEADER. El LEADER II actúa sobre ámbitos comarcales, en aquellas zonas rurales con mayores problemas de desarrollo socioeconómico, en especial: despoblamiento, envejecimiento y bajo nivel de rentas.

La concepción del programa LEADER responde para Pérez Yruela, M.; Giménez Guerrero, M. (1995) al esquema genérico del enfoque local. Primero, se dirige a espacios socioterritoriales de pequeña escala: zonas que tengan entre 5.000 y 100.000 habitantes. Segundo, se dirige a zonas en las que los problemas del desarrollo requieren movilizar con más urgencia que otras sus propios recursos (zonas objetivos 1 y 5b). Tercero, se orienta hacia la movilización de recursos no agrarios, tratando de forzar el aprovechamiento de otros y las oportunidades de aquéllos que puedau existir en las zonas. Cuarto, se basa en un proceso de intervención con que el se quiere promover la participación de la población.

El objetivo general del programa LEADER II es elevar el nivel económico, cultural, de servicios y, en general, la calidad de vida de la población, manteniendo y mejorando, cuando ello sea posible, el patrimonio natural. 
Los objetivos expresados pueden fijarse en los siguientes ejes:

- Informar, capacitar, sensibilizar y estimular los recursos humanos.

- Propiciar una organización social participativa, con especial énfasis en la integración de jóvenes y mujeres.

- Conservar y mejorar el patrimonio natural.

- Intensificar el aprovechamiento de recursos tradicionales endógenos y d nuevos recursos.

- Ordenar y potenciar el sector turístico.

- Conservar y mejorar el patrimonio histórico-artístico y cultural.

- Impulsar procesos de producción, transformación y comercialización de productos de la región que mejoren el nivel de consumo y la competitividac en el mercado.

- Extender el uso y aplicación de nuevas tecnologías.

- Desarrollar una formación profesional y empresarial que permita la cualificación adecuada de la población orientada hacia las nuevas actividades, posibilitando su integración.

El PRODER fue aprobado por la Comisión Europea en junio en 1996 para un periodo de duración de cuatro años (1994-1999) y sus objetivos coinciden en buena parte con los de la iniciativa LEADER II «impulsar el desarrollo endógeno y sostenido de las zonas rurales a través de la diversificación económica para frenar la regresión demográfica, elevando las rentas y el bienestar social de sus habitantes y asegurando la conservación del espacio y de los recursos naturales».

\section{ESQUEMA № 1 \\ OBJETIVOS DE LAS POLÍTICAS DE DESARROLLO RURAL}

Unión Europea

Mantener a la población

\section{Andalucía}

Mejora de las condiciones de vida y de trabajo Dinamización social

Conservación del patrimonio

Aumento del nivel de renta de la población Diversificación

Generación de empleo

(formación y cualificación profesional)

Elaboración propia. 
Para concluir hemos tratado de sintetizar en el Esquema $n^{2} 1$ los principales objetivos de las políticas de desarrollo rural expuestas, comparando la escala autonómica (en nuestro caso Andalucía) y con la europea. El objetivo último de estas políticas podría concretarse en «el incremento del bienestar de la población de la zona y la conservación/potenciación de sus recursos (naturales y humanos)». Para ello, todos los planes analizados coinciden en la necesidad de articular los instrumentos necesarios para:

- Frenar el despoblamiento de las zonas rurales y la consiguiente pérdida de su cultura.

- Incrementar y diversificar las rentas, potenciando los recursos endógenos; lo que conlleva, por un lado, mejorar la formación y cualificación de la población (dinamizarla), y por otro, poner en valor los recursos naturales que permanezcan ociosos (cuidando los límites que estos puedan presentar).

- Generar empleos estables.

- Mejorar las infraestructuras y los equipamientos (servicios públicos, sanitarios, educativos, infraestructuras de acceso, etc.).

Como queda reflejado en el Esquema nº 1 los objetivos para la Unión Europea son más generales que los que se establecen en las políticas de desarrollo rural en Andalucía. Esto se debe a que a Europa le corresponde fijar las líneas de actuación globales y a la comunidad autónoma especificarlas (elegir los objetivos e instrumentos que más se adecuen a su realidad social y económica).

\section{2. ÁMBITO DE ESTUDIO}

La experiencia en la provincia de Sevilla de la iniciativa LEADER se centra en las estribaciones de Sierra Morena y Sierra Sur, zonas montañosas con peligro de despoblamiento, vinculadas al advenimiento del mercado único por la tendencia de la PAC. Esta iniciativa comunitaria de desarrollo ha supuesto un impulso, reflejándose en las actividades productivas de las comarcas Sierra Morena de Sevilla, Corredor de la Plata y Estepa-Sierra Sur.

El LEADER Sierra Morena de Sevilla (Sierra Norte) está compuesto de diez municipios: Alanís, Almaden de la Plata, Cazalla de la Sierra, Constantina, Guadalcanal, Las Navas de la Concepción, El Pedroso, La Puebla de los Infantes, El Real de la Jara y San Nicolás del Puerto. En la comarca se encuentra el Parque Natural Sierra Norte, espacio con recursos potenciales significativos, tanto paisajísticos como cinegéticos, pero principalmente destacado por los recursos ganaderos y forestales de sus dehesas que se convierten en sustentadora del uso agrosilvopastoril para el esparcimiento y ocio; a pesar de ello es y ha sido una zona 
marginal, amenazada por el despoblamiento, cuenta con limitaciones físicas y estructurales para un desarrollo intensivo de su sector primario y existe un reducidc dinamismo empresarial para el aprovechamiento de los recursos locales.

MAPA № 1

LAS COMARCAS LEADER II DE LA PROVINCIA DE SEVILLA

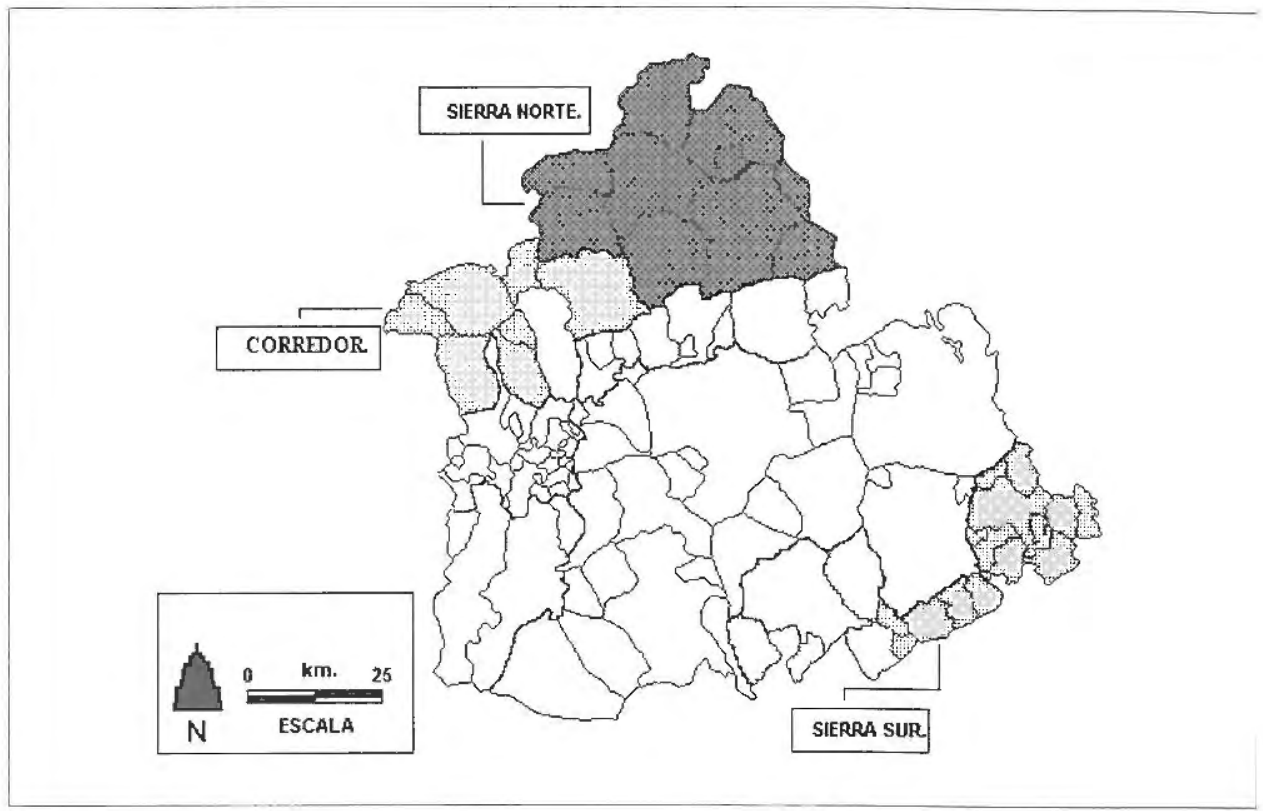

Elaboración propia.

La comarca a través del LEADER II y con sede en Cazalla de la Sierra ha desarrollado una estrategia basada en el proceso de reactivación económico, mediante nuevas experiencias empresariales y diversificación de actividades, centrada en cuatro líneas que ya se habían puesto en marcha en el LEADER I, y que se concentran en el corredor central (El Pedroso, Cazalla de la Sierra y San Nicolás del Puerto):

- Agrícola y Ganadera: la viabilidad del proceso de manipulación y comercialización para la calidad del aceite de oliva y del sector porcino.

- Turística: la riqueza del patrimonio histórico-artístico y la importancia del medio ambiente para el desarrollo del sector.

- Formativa: los recursos humanos de la comarca.

- Industrial: el sector corchero. 
Todo ello encaminado hacia el objetivo genérico de conseguir mayores niveles de renta, con mejores tasas de empleo y una adecuación con el medio ambiente.

Estepa-Sierra Sur, también fue una de las comarcas beneficiadas por las ayudas del LEADER I y II, se sitúa en el sudeste de la provincia de Sevilla y está compuesta por los municipios de Aguadulce, Algámitas, Badolatosa, Casariche, Los Corrales, Estepa, Gilena, Herrera, Lora de Estepa, Marinaleda, Martín de la Jara, Pedrera, La Roda de Andalucía, El Rubio, El Saucejo y Villanueva de San Juan. Estepa es el centro de toma de decisiones para el desarrollo de la comarca.

La estrategia que plantea descansa sobre la base de una dinámica integradora que implique a toda la población rural, tras la mejora de la identidad, protagonismo y autoestima, todo ello en consonancia con una conservación del medio ambiente. Dicha macroestrategia se instrumenta y subdivide en una serie de estrategias que incorporan efectos sinérgicos positivos, que permiten subsanar debilidades y disfuncionalidades patentes, así como limar amenazas existentes en el entorno. Dicho desarrollo pasa por un apoyo activo a las pequeñas y medianas empresas, como unidades productivas que generan la práctica totalidad del empleo en la zona. Su estrategia incide en una mejora de los subsectores económicos actuales (industria del aceite, conservas vegetales, maquinaria industrial agroalimentaria, pastelería tradicional, plástico y envases, mueble y metal); así como un firme impulso a sectores incipientes (agricultura y ganadería ecológica, destilación y manipulación de plantas aromáticas y medicinales, recuperación de huertas, artesanía y turismo rural), la mayor parte de estas actuaciones se concentran en Estepa, Gilena, Algámitas, Herrera, La Roda de Andalucía y Lora de Estepa.

Ubicado en el noroeste de la provincia de Sevilla y ocupando el primer escalón de Sierra Morena, el LEADER Corredor de la Plata lo componen los municipios de Aznalcóllar, Castilblanco de los Arroyos, El Castillo de las Guardas, El Garrobo, Gerena (centro administrativo), El Madroño y El Ronquillo. El programa Corredor de la Plata, surge con el LEADER II, de ahí que comience su andadura en el periodo 1994-1999, poniendo las bases e infraestructuras para el desarrollo económico y social de la comarca.

Los objetivos básicos se centran en la creación y fomento de empresas sólidas que mejoren la calidad de vida en la comarca y en el fomento del empleo, sin perder de vista la formación y cualificación de la población.

La estrategia de la comarca es la introducción de nuevos productos y la promoción de la actividad industrial, fundamentalmente ligada a la creación de focos de difusión tecnológicos (textil, construcción, mármol y granito, etc.), la potenciación del desarrollo agroindustrial de la comarca (salazones, avestruces, etc.) y el aprovechamiento de los recursos naturales de forma controlada y reorientada al sector turístico. 


\section{ANÁLISIS DE RESULTADOS}

Como ya hemos señalado, los programas LEADER son iniciativas comunita rias dirigidas al desarrollo de zonas rurales. Para comprobar la eficacia de dicha: políticas, es importante aclarar la diferencia existente entre los conceptos de cre cimiento y desarrollo; y por lo tanto, entre los distintos instrumentos para su me dición. El crecimiento hace referencia a un incremento en la renta o riqueza de lí zona considerada, es un concepto puramente económico, objetivo y cuantitativo Para que se produzca el desarrollo es necesario, además del crecimiento econó. mico, que acontezcan una serie de cambios de ámbito cualitativo (distribuciór equitativa de los frutos de ese crecimiento, mejora de los niveles educativos de la población, mayor y mejor cobertura sanitaria, respeto ambiental, etc.). El desarro. llo es un término integral (incluye aspectos económicos, sociales, culturales, reli. giosos, etc.) y totalmente subjetivo (cada sociedad se rige por sus propios parámetros al respecto), por lo que es muy difícil generalizar una definición y ur sistema de medición. En este sentido, las Naciones Unidas proponen el conceptc de Desarrollo Humano, y lo definen como: «Proceso que experimenta una sociedad para conseguir el bienestar de su población relacionándose de forma armónica con el entorno natural, consiguiendo así satisfacer las necesidades materiales y establecer las bases para que todo individuo pueda desplegar su potencial humano». De esta definición se desprende que el crecimiento económico únicamente es una condición necesaria, pero nunca suficiente para que se produzca el desarrollo: el crecimiento proporciona mayor riqueza a la zona (no todos los habitantes tienen por que ser más ricos, es posible que toda esa riqueza generada se concentre en unas pocas manos), el desarrollo incrementa el bienestar de la mayor parte de la población que allí habita y permite que esa situación perdure en el tiempo. Siguiendo estos planteamientos, la medición del crecimiento y la comparación de esta variable en distintos territorios es simple: basta con hallar un indicador de renta (PIB, PNB, PNB o PNN) y analizar su evolución. Por el contrario, medir el desarrollo es prácticamente imposible debido a la gran cantidad de variables subjetivas que incorpora su definición. Para comprobar la eficacia de los LEADER, dado que su objetivo se centra en el desarrollo, analizamos la evolución que se ha producido durante la última década en relación a: por un lado, variables únicamente vinculadas al crecimiento (PIB per cápita); y por otro, variables que nos permiten estimar si ese crecimiento se ha traducido en un mayor bienestar de la población (mercado de trabajo, aspectos demográfico, niveles educativos, cobertura sanitaria y dotación de infraestructuras).

Para ello, nos hemos basado en las dos únicas fuentes que desagregan sus datos municipalmente: en los Anuarios de Estadísticas de la Provincia de Sevilla (1992-1995) realizados por la Diputación de Sevilla y, en el Sistema de Información Multiterritorial de Andalucía (SIMA) 1999 realizado por el Instituto Anda- 
luz de Estadística. El ámbito temporal escogido es de 1986 a 1998. Cada una de las variables seleccionadas será analizada para 1986 (año en el que aún no habían comenzado las iniciativas LEADER), 1991 (año de inicio del LEADER I), 1994 (fin del primer LEADER y comienzo del segundo) y, en el caso en que sea posible 1998 (sino están disponibles, mostraremos el dato más reciente). Debido a estas limitaciones el estudio de las variables vinculadas al desarrollo se realizará de un modo principalmente cualitativo, a través de las conclusiones obtenidas tras los contactos directos con los responsables de estos programas y los agentes sociales implicados en ellos.

\subsection{Crecimiento}

Para el análisis de la renta per cápita hemos utilizado las estimaciones realizadas por el Dr. José Pérez Blanco publicadas en los anuarios de la Diputación. El problema de esta fuente es que el último anuario realizado fue el de 1995 con estimaciones de 1994, y en el SIMA 99 únicamente aparecen datos de renta agrupados por intervalos (entre 0 y 1.000 .000 y 1.125 .000 ) lo que no nos sirve para nuestra comparación temporal al no apreciarse apenas diferencias. En los Cuadros $\mathrm{n}^{\circ} 1,2$ y 3 queda recogida la renta per cápita (en pesetas constantes de 1980) de los municipios de cada una de las comarcas LEADER sevillanas y la media provincial, para los años 1986, 1991 y 1994 (en relación a esta variable nos será imposible analizar los resultados de los programas LEADER II -1994/1999-).

La etapa 1986-1991 se caracteriza por un fuerte crecimiento de la renta en toda la provincia $(33,41 \%)$ debido, fundamentalmente, a la coyuntura favorable de la economía nacional e internacional durante la segunda mitad de la década de los ochenta. Por el contrario, el periodo 91-94 coincide con una fuerte crisis mundial; lo que se refleja en tasas de crecimiento económico negativas, tanto en la provincia de Sevilla $(-6,59 \%)$ como en el conjunto de España. En este sentido, lo primero que llama la atención al analizar la renta per cápita de los municipios de las comarcas LEADER es que la mayor parte de ellos presentan tasas positivas entre el 91 y el 94 (ámbito temporal del LEADER I). Esto contribuye a mejorar la distribución espacial de la renta en la provincia de Sevilla, al acortar las diferencias existentes entre estas comarcas (las más pobres) y el resto.

\section{A) Sierra Norte}

En 1986 (año en el aún no han comenzado las iniciativas LEADER) y en 1991 (año en que comienza la primera) el municipio de mayor renta era Constantina, seguido de Cazalla y El Pedroso. En 1994 (una vez finalizado el LEADER I) El 
Pedroso ocupa la primera posición, seguido de Cazalla y Constantina. Esto se debe en su mayor parte, a esta iniciativa comunitaria: de un lado, Cazalla se conviert en el centro de toma de decisiones y actuaciones (es el municipio desde donde st gestiona); y de otro, El Pedroso se ve reactivado por el hecho de ser la puerta d acceso a la Sierra Norte (impulsada turísticamente por gran parte de las actuacio nes realizadas). Los incrementos de renta más importantes se han producido en El Pedroso $(25,5 \%)$, San Nicolás del Puerto $(21,09 \%)$, Puebla de los Infante: $(19,09 \%)$ y Alanís $(18,64 \%)$; lo que ha contribuido a dispersar las rentas en li comarca y acortar las diferencias existentes entre los pueblos de la misma, ya qut estos municipios no coinciden con los de mayor renta.

\section{CUADRO № 1 \\ RENTA PER CÁPITA DE LA SIERRA NORTE (en pesetas constantes de 1980)}

\begin{tabular}{lccccc}
\hline Municipios & 1986 & 1991 & 1994 & $86-91$ & $91-94$ \\
\hline Alanís & 197.681 & 252.830 & 299.966 & $27,90 \%$ & $18,64 \%$ \\
Almadén de la Plata & 192.049 & 303.605 & 338.954 & $58,09 \%$ & $11,64 \%$ \\
Cazalla de la Sierra & 231.459 & 321.014 & 353.847 & $38,69 \%$ & $10,23 \%$ \\
Constantina & 264.369 & 332.075 & 345.870 & $25,61 \%$ & $4.15 \%$ \\
Guadalcanal & 224.387 & 316.083 & 348.992 & $40,87 \%$ & $10,41 \%$ \\
Las Navas & 192.454 & 311.917 & 307.175 & $62,07 \%$ & $-1,52 \%$ \\
El Pedroso & 230.208 & 298.459 & 374.573 & $29,65 \%$ & $25,50 \%$ \\
La Puebla de los Infantes & 211.282 & 272.653 & 324.711 & $29,05 \%$ & $19,09 \%$ \\
El Real de la Jara & 193.724 & 288.686 & 322.150 & $49,02 \%$ & $11,59 \%$ \\
San Nicolás del Puerto & 203.300 & 262.146 & 317.425 & $28,95 \%$ & $21,09 \%$ \\
Provincia Sevilla & $\mathbf{3 3 2 . 3 7 8}$ & $\mathbf{4 4 3 . 4 2 5}$ & $\mathbf{4 1 4 . 2 2 3 , 7 6}$ & $\mathbf{3 3 , 4 1 \%}$ & $\mathbf{- 6 , 5 9 \%}$ \\
\hline
\end{tabular}

Fuente: Estimaciones de los ingresos personales de los municipios de la provincia de Sevilla, realizadas po el Dr. José Pérez. Blanco, en Anuarios Estadísticos de la Provincia de Sevilla (1992-1995), Diputación Pro vincial de Sevilla, Sevilla, varios años y elaboración propia.

\section{B) Estepa-Sierra Sur}

Esta comarca presenta una gran ventaja frente a la anterior: su situación estratégica al encontrarse ubicada en el paso entre las provincias de Sevilla, Málaga s Granada. En 1986 los municipios con mayor renta per cápita fueron Gilena, Estepa y Herrera; en 1991 Gilena sigue ocupando el primer puesto, pero Herrera adelanta a Estepa; y en 1994 destacan: Gilena, Lora de Estepa, Herrera y Estepa. Er estas localidades se concentran la mayoría de las empresas industriales de la comarca (mantecados, aceites, material de construcción); lo que nos muestra la im- 
portancia de la actividad empresarial para el desarrollo de una región. Al igual que ocurría en la Sierra Norte, mejora la distribución espacial de la renta, ya que los municipios que experimentan mayores incrementos no coinciden con los más ricos: Algamitas (28,61\%), El Saucejo (17,08\%) y Martín de la Jara (15,07\%). Esto también se puede deber a que la crisis económica nacional afecta de modo más intenso a los sectores industriales.

CUADRO № 2

RENTA PER CÁPITA DE ESTEPA-SIERRA SUR

(en pesetas constantes de 1980)

\begin{tabular}{lccccr}
\hline Municipios & 1986 & 1991 & 1994 & $86-91$ & $91-94$ \\
\hline Aguadulce & 237.938 & 290.071 & 338.569 & $21,91 \%$ & $16,72 \%$ \\
Algámitas & 207.247 & 244.422 & 314.340 & $17,94 \%$ & $28,61 \%$ \\
Badolatosa & 201.007 & 283.031 & 310.716 & $40,81 \%$ & $9,78 \%$ \\
Casariche & 209.419 & 297.337 & 332.991 & $41,98 \%$ & $11,99 \%$ \\
Los Corrales & 194.511 & 253.748 & 282.916 & $30.45 \%$ & $11,49 \%$ \\
Estepa & 260.479 & 337.932 & 356.470 & $29,73 \%$ & $5.49 \%$ \\
Gilena & 279.824 & 427.241 & 429.026 & $52,68 \%$ & $0.42 \%$ \\
Herrera & 258.280 & 339.104 & 357.165 & $31,29 \%$ & $5,33 \%$ \\
Lora de Estepa & 228.736 & 332.955 & 363.034 & $45,56 \%$ & $9,03 \%$ \\
Marinaleda & 201.419 & 264.735 & 290.873 & $31.43 \%$ & $9,87 \%$ \\
Martín de la Jara & 191.068 & 252.448 & 290.500 & $32,12 \%$ & $15,07 \%$ \\
Pedrera & 226.670 & 294.852 & 321.665 & $30,08 \%$ & $9,09 \%$ \\
La Roda de Andalucía & 232.242 & 357.221 & 332.245 & $53,81 \%$ & $-6,99 \%$ \\
El Rubio & 222.705 & 288.818 & 303.474 & $29,69 \%$ & $5,07 \%$ \\
El Saucejo & 188.793 & 236.803 & 277.253 & $25,43 \%$ & $17,08 \%$ \\
Villanueva de San Juan & 198.183 & 227.051 & 224.094 & $14,57 \%$ & $-1,30 \%$ \\
\cline { 2 - 6 } Provincia Sevilla & $\mathbf{3 3 2 . 3 7 8}$ & $\mathbf{4 4 3 . 4 2 5}$ & $\mathbf{4 1 4 . 2 2 3 , 7 6}$ & $\mathbf{3 3 , 4 1 \%}$ & $\mathbf{- 6 , 5 9 \%}$ \\
\hline
\end{tabular}

Fuente: Estimaciones de los ingresos personales de los municipios de la provincia de Sevilla, realizadas por el Dr. José Pérez Blanco, en Anuarios Estadísticos de la Provincia de Sevilla (1992-1995). Diputación Provincial de Sevilla, Sevilla, varios años y elaboración propia.

\section{C) Corredor de la Plata}

Esta comarca, al presentar rentas más elevadas, únicamente ha recibido fondos del LEADER II (1994-1999). Esto nos imposibilita el estudio con relación a la variable renta, ya que nuestro análisis termina antes de que comience esta iniciativa. 


\section{CUADRO № 3}

RENTA PER CÁPITA DEL CORREDOR DE LA PLATA

(en pesetas constantes de 1980)

\begin{tabular}{lccccc}
\hline Municipios & 1986 & 1991 & 1994 & $86-91$ & $91-94$ \\
\hline Aznalcóllar & 184.671 & 321.416 & 349.167 & $74,05 \%$ & $8,63 \%$ \\
Castilblanco & 256.763 & 369.430 & 397.703 & $43,88 \%$ & $7,65 \%$ \\
Castillo de las Guardas & 309.346 & 394.176 & 438.260 & $27,42 \%$ & $11,18 \%$ \\
El Garrobo & 387.269 & 543.995 & 528.292 & $40,47 \%$ & $-2,89 \%$ \\
Gerena & 238.343 & 318.557 & 363.979 & $33,65 \%$ & $14,26 \%$ \\
El Madroño & 243.123 & 327.810 & 376.041 & $34,83 \%$ & $14,71 \%$ \\
El Ronquillo & 250.945 & 364.461 & 406.349 & $45,24 \%$ & $11,49 \%$ \\
\cline { 2 - 6 } Provincia Sevilla & $\mathbf{3 3 2 . 3 7 8}$ & $\mathbf{4 4 3 . 4 2 5}$ & $\mathbf{4 1 4 . 2 2 3 , 7 6}$ & $\mathbf{3 3 , 4 1 \%}$ & $\mathbf{- 6 , 5 9 \%}$ \\
\hline
\end{tabular}

Fuente: Estimaciones de los ingresos personales de los municipios de la provincia de Sevilla, realizadas po el Dr. José Pérez Blanco, en Anuarios Estadísticos de la Provincia de Sevilla (1992-1995), Diputación Pro vincial de Sevilla, Sevilla, varios años y elaboración propia.

\subsection{Desarrollo}

Si se asume que la finalidad última del desarrollo es el incremento del bienes. tar y su sustentabilidad, la definición de objetivos que, implícita o explícitamente, ha de llevarse a cabo en un plan de desarrollo local en áreas rurales ha de estar necesariamente relacionada con el concepto de bienestar.

La mayoría de los procesos de desarrollo local que han tenido lugar en las zonas rurales han surgido de manera anárquica, en cuanto a ausencia de planificación Normalmente dichos procesos, según Calatrava Requena (1993), o son la resultante de intentos puntuales de resistencia a la marginalidad socioeconómica por parte de algún sector de la comunidad local, o son procesos generados y, con frecuencia, controlados, por una demanda exterior que se dirige a la zona y a la que responde una parte de población, propiciando la correspondiente oferta.

Independientemente del grado de «espontaneidad» conque los procesos de desarrollo local se producen en su fase inicial, en algún momento han de ser asimilados por la población local y las administraciones competentes, tratando de adecuar su naturaleza y dimensión a las necesidades, aspiraciones e intereses de la comunidad con las necesarias limitaciones institucionales.

\subsubsection{La población}

El elemento humano es componente fundamental en el análisis socioeconómico de cualquier zona geográfica. El desarrollo de la región parte de él y finaliza en 
él; el bienestar económico es un concepto que no puede desligarse de sus beneficiarios. En consecuencia, es preciso conocer las características de las personas que habitan en la comarca, por ello, analizaremos la situación y evolución de algunas variables demográficas.

Las fuentes empleadas se han basado en el Censo de Población de 1991 y en las Revisiones Padronales, extraídas del Anuario Estadístico de Andalucía (1997) del IEA y del SIMA (1999). En ellos, hemos encontrado datos hasta 1998 para la estructura de población y hasta 1996 para los movimientos espaciales, lo que imposibilita analizar la rentabilidad del LEADER II.

Si nos fijamos en las tendencias y procesos que han caracterizado la demografía en la población rural andaluza durante los últimos veinte o treinta años, parecería que el futuro de muchos pueblos iba a ser incierto; pero las tendencias demográficas han empezado a cambiar (Cuadro $n^{0}$ 4) y los pueblos están recobrando cierta vitalidad demográfica que hasta hace poco era impensable.

\section{CUADRO № 4 \\ EVOLUCIÓN DE LA POBLACIÓN DE LAS COMARCAS LEADER I EN SEVILLA (1986-1998)}

\begin{tabular}{lcccc}
\hline & 1986 & 1991 & 1995 & 1998 \\
\hline Sierra Norte & 31.724 & 29.994 & 30.305 & 29.551 \\
Corredor de la Plata & 18.566 & 19.076 & 19.895 & 19.770 \\
Estepa-Sierra Sur & 59.040 & 59.748 & 62.182 & 62.013 \\
\hline
\end{tabular}

Fuente: Año 1986. Padrón Municipal; Año 1991. (IEA) Anuario Estadístico 1991; Año 1995. Rectificaciones Padronales. Recogida en el SIMA (1999). Elaboración propia.

La aplicación de la iniciativa LEADER II, aún es difícil de valorar demográficamente, aunque se observa una mejora generalizada en el Corredor de la Plata y Estepa-Sierra Sur. La Sierra Norte ha ido perdiendo efectivos, aunque en 1998 mantiene cifras similares a 1991.

La densidad de población de los grupos LEADER en España es de unos $20 \mathrm{hab} /$ $\mathrm{km}^{2}$, como aparece en el Cuadro $\mathrm{n}^{\mathrm{0}} 5$, la Sierra Norte y el Corredor de la Plata se encuentra por debajo de estas cifras, $15,39 \%$ y $17,37 \%$ respectivamente, aunque existe una mejora como se comentaba con anterioridad en la población de dichas comarcas. Dicha variable nos da una dimensión territorial a los discontinuos volúmenes de población dispuesto sobre el espacio. En términos reales, todas las comarcas han mejorado respecto a 1991, cuando se pone en marcha el programa comunitario LEADER I. Estepa-Sierra Sur es la que más progresa. 
DENSIDAD DE POBLACIÓN DE LOS LEADER EN SEVILLA (1986-1995)

\begin{tabular}{lccc}
\hline & 1986 & 1991 & 1995 \\
\hline Sierra Norte & 16,11 & 15,24 & 15,39 \\
Corredor de Plata & 16,21 & 16,66 & 17,37 \\
Sierra Sur-Estepa & 39,94 & 40,42 & 42,07 \\
Provincia de Sevilla & $\mathbf{1 0 9 , 6 3}$ & $\mathbf{1 1 5 , 2 4}$ & $\mathbf{1 2 1 , 2 8}$ \\
\hline
\end{tabular}

Fuente: Año 1986. Padrón Municipal; Año I991. (IEA) Anuario Estadístico 1991; Año 1995. Rectificaciones Padronales. Recogida en el SIMA (1999). Elaboración propia.

\section{A) Composición por edades}

Entre 1991 y 1996 no se aprecian cambios considerables en la estructura de mográfica, aunque el interés de estos años se debe al periodo comprendido di actuación de la iniciativa comunitaria.

En la provincia de Sevilla (Cuadro n 6), durante el periodo investigado exist un mayor porcentaje de niños, aunque las tendencias en sólo cinco años han pro ducido un descenso considerable de dicho grupo de edad, pasando de $22,91 \%$ : $19,1 \%$, lo cual muestra la tendencia al envejecimiento, y reducción de la pirámi de de población en su base.

Los municipios de las comarcas presentan una estructura poblacional desequi librada; por un lado, la población joven es reducida, en torno al $22 \%$, debido : los cambios en las pautas de comportamiento respecto a la natalidad, por el ma yor uso de métodos anticonceptivos; y por otro, el envejecimiento es elevadc ( $15 \%)$, aunque su incremento en la Sierra Norte y Corredor de la Plata es inferio] a la media provincial, lo cual lleva a una estructura de población estancada cor fuertes repercusiones económicas, ante las altas tasas de dependencia que deb $\epsilon$ soportar la población activa. Estepa-Sierra Sur es la comarca que experimentć mayores cambios.

\section{B) Movimientos espaciales de la población}

Dentro de los movimientos migratorios de la población, en las comarcas que se están analizando, destacan los movimientos básicos y la emigración de temporada.

Como se observa en el Cuadro $n^{2} 7$, el saldo sigue siendo negativo pero existe una considerable mejora entre los periodos de 1989-1996, principalmente en la comarca que de la Sierra Norte, mientras que los datos globales de la Sierra Sur y el Corredor de la Plata empeoran. 


\section{CUADRO № 6}

ESTRUCTURA POR GRUPOS DE EDADES EN LAS COMARCAS LEADER II. SEVILLA (1991-1996)

\begin{tabular}{|c|c|c|c|c|}
\hline & 0-14 años & 15-64 aก̃os & Más de 65 años & No consta \\
\hline \multicolumn{5}{|c|}{ Sierra Norte } \\
\hline 1991 & 19,39 & 62,39 & 17,80 & 0,40 \\
\hline 1996 & 19,50 & 62,60 & 17,90 & - \\
\hline \multicolumn{5}{|c|}{ Corredor de la Plata } \\
\hline 1991 & 21,81 & 62,99 & 14,73 & 0,46 \\
\hline 1996 & 21,80 & 64,00 & 14,20 & - \\
\hline \multicolumn{5}{|c|}{ Estepa-Sierra Sur } \\
\hline 1991 & 23,38 & 63,63 & 12,64 & 0,33 \\
\hline 1996 & 21,30 & 64,12 & 14,56 & - \\
\hline \multicolumn{5}{|c|}{ Provincia de Sevilla } \\
\hline 1991 & 22,91 & 65,82 & 11,18 & - \\
\hline 1996 & 19,10 & 68,59 & 12,31 & - \\
\hline
\end{tabular}

Fuente: SIMA (1997). Elaboración propia.

CUADRO № 7

SALDO MIGRATORIO DE LAS COMARCAS LEADER

\begin{tabular}{lrc}
\hline Saldo migratorio & 1989 & 1996 \\
\hline Sierra Norte & -214 & -91 \\
Sierra Sur & -103 & -167 \\
Corredor de la Plata & 70 & -40
\end{tabular}

Fuente: Sistema de Información Multiterritorial de Andalucía (SIMA) 1999, Instituto Andaluz de Estadística, Junta de Andalucía y elaboración propia.

Si uno de los objetivos del LEADER era frenar el despoblamiento, para lo cual era necesario paliar la emigración (Cuadros $n^{\circ} 8,9$ y 10), se ha conseguido una reducción generalizada, más intensa en la Sierra Norte (en todos los municipios disminuye la emigración, excepto en San Nicolás del Puerto), seguida del Corredor de la Plata (-2,54\%, únicamente aumenta en El Garrobo y Castilblanco). En cambio, en Estepa-Sierra Sur la emigración aumenta debido al fuerte incremento sufrido en Lora de Estepa $(117,65 \%)$, ya que en la mayor parte de sus municipios se está reduciendo (en especial: Pedrera, EI Saucejo y Badolatosa). 


\section{CUADRO No 8}

EVOLUCIÓN DE LAS EMIGRACIONES EN LA SIERRA NORTE

\begin{tabular}{lrrr}
\hline & 1989 & 1996 & $89-96$ \\
\hline Alanís & 27 & 20 & $-25,93 \%$ \\
Almadén de la Plata & 32 & 16 & $-50,00 \%$ \\
Cazalla de la Sierra & 107 & 61 & $-42,99 \%$ \\
Constantina & 158 & 111 & $-29,75 \%$ \\
Guadalcanal & 38 & 28 & $-26,32 \%$ \\
Las Navas de Ia Concepción & 61 & 12 & $-80,33 \%$ \\
El Pedroso & 45 & 39 & $-13,33 \%$ \\
La Puebla de los Infantes & 72 & 63 & $-\mathbf{1 2 , 5 0 \%}$ \\
El Real de la Jara & 54 & 21 & $\mathbf{7 5 , 0 0 \%}$ \\
San Nicolás del Puerto & 4 & 7 & $\mathbf{- 3 6 , 7 9 \%}$ \\
TOTAL & $\mathbf{5 9 8}$ & $\mathbf{3 7 8}$ & - \\
\hline
\end{tabular}

Fuente: Sistema de Información Multiterritorial de Andalucía (SIMA) 1999, Instituto Andaluz de Estadística, Junta de Andalucía y elaboración propia.

\section{CUADRO № 9}

EVOLUCIÓN DE LAS EMIGRACIONES EN LA SIERRA SUR

\begin{tabular}{lccc}
\hline & 1989 & 1996 & $89-96$ \\
\hline Aguadulce & 26 & 24 & $-7,69 \%$ \\
Algámitas & 38 & 14 & $-63,16 \%$ \\
Badolatosa & 60 & 30 & $-50,00 \%$ \\
Casariche & 52 & 65 & $25,00 \%$ \\
Los Corrales & 56 & 50 & $-10,71 \%$ \\
Estepa & 90 & 89 & $-1,11 \%$ \\
Gilena & 54 & 43 & $-20,37 \%$ \\
Herrera & 63 & 68 & $7,94 \%$ \\
Lora de Estepa & 17 & 307 & $1.117,65 \%$ \\
Marinaleda & 31 & 38 & $22,58 \%$ \\
Martín de la Jara & 59 & 57 & $-33,90 \%$ \\
Pedrera & 74 & 51 & $-22,97 \%$ \\
La Roda de Andalucía & 66 & 43 & $-22,73 \%$ \\
El Rubio & 64 & 33 & $-32,81 \%$ \\
El Saucejo & 66 & 46 & $-50,00 \%$ \\
Villanueva de San Juan & 55 & 897 & $-16,36 \%$ \\
TOTAL & 871 & $2,99 \%$ \\
\hline
\end{tabular}

Fuente: Sistema de Información Multiterritorial de Andalucía (SIMA) 1999, Instituto Andaluz de Estadística, Junta de Andalucía y elaboración propia. 
CUADRO № 10

EVOLUCIÓN DE LAS EMIGRACIONES EN EL CORREDOR DE LA PLATA

\begin{tabular}{lccc}
\hline & 1989 & 1996 & $89-96$ \\
\hline Aznalcóllar & 60 & 39 & $-35,00 \%$ \\
Castilblanco & 35 & 84 & $140,00 \%$ \\
Castillo de las Guardas & 32 & 21 & $-34,38 \%$ \\
El Garrobo & 8 & 9 & $12,50 \%$ \\
Gerena & 54 & 38 & $-29,63 \%$ \\
El Madroño & 13 & 10 & $-23,08 \%$ \\
El Ronquillo & 34 & 29 & $-14,71 \%$ \\
TOTAL & $\mathbf{2 3 6}$ & $\mathbf{2 3 0}$ & $\mathbf{- 2 , 5 4 \%}$ \\
\hline
\end{tabular}

Fuente: Sistema de Información Multiterritorial de Andalucía (SIMA) 1999, Instituto Andaluz de Estadística, Junta de Andalucía y elaboración propia.

La emigración de temporada ocupa un lugar fundamental, tanto por el volumen que mueve como por su tradición. La emigración de temporada es muy difícil de estudiar pues no existen estadísticas de las distintas campañas de cada año, y no existe control de ellas. Las campañas más importantes son las agrícolas (recolección de la aceituna, de la fresa, del espárrago, de la uva) y las de hostelería dirigidas a la Costa del Sol.

\subsubsection{Mercado de trabajo}

Para el estudio del mercado de trabajo contamos con dos fuentes muy distintas: Ios registros de las oficinas del Instituto Nacional de Empleo (INEM) y la Encuesta de Población Activa (EPA). El dato «paro registrado» presenta limitaciones importantes ya que no tiene por que recoger a todos los parados existentes (dependerá del estímulo que tengan para registrarse), ni todos los que allí se registran tienen por que estar realmente parados (España es un país con una importante economía sumergida, de modo que una persona puede estar trabajando extraoficialmente y estar registrada para beneficiarse de las ventajas que esto conlleve). No obstante, esta fuente nos permite disponer de datos municipalizados muy actuales. La EPA, al utilizar técnicas de muestreo controladas, es más exacta (se puede conocer el error cometido) y permite conocer otras variables (además de la población parada) fundamentales para los estudios del mercado de trabajo: pobla- 
ción activa ${ }^{1}$ y población ocupada. En este sentido, es posible que en un determinado municipio la población parada disminuya y que no se haya creado empleo sino que se haya reducido la población dispuesta a trabajar. Por ello, para realiza comparaciones correctas necesitamos tasas que permitan relacionar todas las variables que influyen en este mercado: tasa de actividad, ocupación y desemple ${ }^{2}$ : y para ello, es imprescindible conocer la población activa. El problema radica en que la desagregación municipal de dichas tasas se realiza con retardos temporales muy importantes (En el SIMA 99 únicamente encontramos la población activa de 1986 y 1991). Conociendo estas limitaciones, hemos optado por ofrecer las tasas de paro de 1989,1991 y $1994^{3}$ y completar esta información con el paro registrado entre 1986 y 1998.

\section{A) Tasas de paro}

Como hemos señalado, las tasas de paro, al relacionar la población parada con la activa, es mejor indicador que el paro registrado para los estudios de mercado de trabajo; pero no disponemos de datos municipales más allá de 1994 (lo que no nos permite analizar los efectos del LEADER II). No obstante, del estudio de esta variable se deduce que:

- La mayor parte de los municipios experimentan reducciones en sus tasas de desempleo entre 1991 y 1994, cuando en Sevilla se está incrementando (2,2\%). La única excepción la constituye Estepa: 14,19\%. Este dato confïrma la mejoría de la comarcas LEADER, en relación al mercado de trabajo, respecto del resto de la provincia.

- Los municipios con mayores tasas de paro logran mejorías más importantes: Almaden (de un 31,34\% en 1986 a un 21,49 en 1994), Algámitas (de un $47,15 \%$ en 1986 a un $31,55 \%$ en 1994), Villanueva de San Juan (de un $39,8 \%$ a un $13,55 \%$ ); lo que confirma la mayor dispersión espacial con relación a la generación de riqueza y empleo dentro de las comarcas.

1. La población activa está compuesta por todos aquellos que, teniendo la edad legal para trabajar, desean hacerlo. Dentro de ella distinguimos: los que realmente trabajan (población ocupada) y los que no han encontrado empleo (población desempleada).

2. La tasa de actividad es igual a la población activa partido por la población en edad de trabajar (aunque también se puede relacionar con la población total). La tasa de ocupación es igual a la población ocupada dividida entre la población activa, y Ia tasa de desempleo es igual a la población parada entre la activa.

3. Estos datos han sido elaborados por el Centro de Información Económica y Documentación de la Dipulación de Sevilla, dividiendo el paro registrado por la población activa estimada para cada año (la estimación de la población activa se corresponde con una interpolación entre la revisión padronal de 1986 y el censo de 1991, hecha sobre la base de la estimación de la tasa de crecimiento anual del periodo). 


\section{CUADRO № 11}

EVOLUCIÓN DE LA TASA DE PARO EN LA SIERRA NORTE (valores absolutos y tasas de crecimiento)

\begin{tabular}{|c|c|c|c|c|c|}
\hline & 1989 & 1991 & 1994 & $89-91$ & $91-94$ \\
\hline Alanís & 10,08 & 21,88 & 16,81 & 11,80 & $-5,07$ \\
\hline Almadén de la Plata & 31,34 & 22,45 & 21,49 & $-8,89$ & $-0,96$ \\
\hline Cazalla de la Sierra & 6,84 & 17.91 & 18,76 & 11,07 & 0,85 \\
\hline Constantina & 8,77 & 14,93 & 14,11 & 6,16 & $-0,82$ \\
\hline Guadalcanal & 11,06 & 11,35 & 11,60 & 0,29 & 0,25 \\
\hline Las Navas de la Concepción & 9,96 & 10,29 & 6,24 & 0,33 & $-4,05$ \\
\hline El Pedroso & 6,83 & 13,64 & 14,09 & 6,81 & 0,45 \\
\hline La Puebla de los Infantes & 17,30 & 10,46 & 7,59 & $-6,84$ & $-2,87$ \\
\hline El Real de la Jara & 18,63 & 15,45 & 17,93 & $-3,18$ & 2,48 \\
\hline San Nicolás del Puerto & 11,11 & 26,77 & 25,00 & 15,66 & $-1,77$ \\
\hline Sevilla & 27,70 & 22,10 & 24,32 & $-5,60$ & 2,22 \\
\hline
\end{tabular}

Fuente: INEM, Sevilla, varios años, en Anuarios Estadisticos de la Provincia de Sevilla (1992-1995), Diputación Provincial de Sevilla, Sevilla, varios años y elaboración propia.

\section{CUADRO № 12}

EVOLUCIÓN DE LA TASA DE PARO EN LA SIERRA SUR (valores absolutos y tasas de crecimiento)

\begin{tabular}{|c|c|c|c|c|c|}
\hline & 1989 & 1991 & 1994 & $89-91$ & $91-94$ \\
\hline Aguadulce & 15,25 & 10,25 & 8,49 & $-5,00$ & $-1,76$ \\
\hline Algámitas & 47,15 & 38,50 & 31,55 & $-8,65$ & $-6,95$ \\
\hline Badolatosa & 12,18 & 13,84 & 8,05 & 1,66 & $-5,79$ \\
\hline Casariche & 7,65 & 10,14 & 10,21 & 2,49 & 0,07 \\
\hline Los Corrales & 19,08 & 12,86 & 9.21 & $-6,22$ & $-3,65$ \\
\hline Estepa & 11,03 & 11,04 & 25,23 & 0,01 & 14,19 \\
\hline Gilena & 6,44 & 8,32 & 8,58 & 1,88 & 0,26 \\
\hline Herrera & 12,77 & 12,58 & 14,02 & $-0,19$ & 1,44 \\
\hline Lora de Estepa & 9,27 & 9,47 & 9,43 & 0,20 & $-0,04$ \\
\hline Marinaleda & 7,32 & 9,11 & 8,92 & 1,79 & $-0,19$ \\
\hline Martín de la Jara & 18,81 & 11,13 & 6,75 & $-7,68$ & $-4,38$ \\
\hline Pedrera & 12,06 & 14,31 & 12,63 & 2,25 & $-1,68$ \\
\hline La Roda de Andalucía & 15,28 & 13,01 & 11,79 & $-2,27$ & $-1,22$ \\
\hline El Rubio & 8,61 & 9,26 & 7,78 & 0,65 & $-1,48$ \\
\hline El Saucejo & 34,00 & 18,18 & 16,05 & $-15,82$ & $-2,13$ \\
\hline Villanueva de San Juan & 39,80 & 24,48 & 13,55 & $-15,32$ & $-10,93$ \\
\hline Sevilla & 27,70 & 22,10 & 24,32 & $-5,60$ & 2,22 \\
\hline
\end{tabular}

Fuente: INEM, Sevilla, varios años, en Anuarios Estadísticos de la Provincia de Sevilla (1992-1995), Diputación Provincial de Sevilla, Sevilla, varios años y elaboración propia. 
CUADRO № 13

EVOLUCIÓN DE LA TASA DE PARO EN EL CORREDOR DE LA PLATA

(valores absolutos y tasas de crecimiento)

\begin{tabular}{lccrrr}
\hline Municipios & 1989 & 1991 & 1994 & $89-91$ & $91-94$ \\
\hline Aznalcóllar & 24,20 & 22,02 & 24,43 & $-2,18$ & 2,41 \\
Castilblanco & 25,12 & 18,08 & 23,70 & $-7,04$ & 5,62 \\
Castillo de las Guardas & 27,88 & 22,58 & 20,49 & $-5,30$ & $-2,09$ \\
El Garrobo & 42,74 & 45,56 & 41,79 & 2,82 & $-3,77$ \\
Gerena & 49,08 & 39,18 & 37,87 & $-9,90$ & $-1,31$ \\
El Madroño & 32,86 & 22,48 & 18,80 & $-10,38$ & $-3,68$ \\
El Ronquillo & 31,43 & 34,14 & 28,28 & 2,71 & $-5,86$ \\
Sevilla & 27,70 & 22,10 & 24,32 & $-5,60$ & 2,22 \\
\hline
\end{tabular}

Fuente: INEM, Sevilla, varios años, en Anuarios Estadísticos de la Provincia de Sevilla (1992-1995) Diputación Provincial de Sevilla, Sevilla, varios años y elaboración propia.

\section{B) Paro registrado}

Al analizar las cifras globales de la provincia de Sevilla volvemos a aprecia1 la influencia del ciclo económico (1986-91 reducción del paro, 1991-94 incrementc y 1994-98 nueva reducción). La incidencia de la coyuntura económica naciona] también se deja sentir en las comarcas analizadas, pero de forma notablemente más suave (Cuadro $n^{\circ} 14$ ). En la Sierra Norte (Cuadro $n^{2} 15$ ), entre 1991 y 1994 el parc se reduce en un $16,86 \%$ y entre 1994 y 1998 en un $37,56 \%$ (16 puntos por encima de la media provincial); esto ha supuesto pasar de 4.760 parados en 1986 a 989 en 1998. En Estepa-Sierra Sur (Cuadro no 16), entre 1991 y 94 se registran caídas del $11,46 \%$ y entre 1994 y 1998 del 5,76\% (estas cifras, a pesar de seı mejores que las de la media provincial no igualan las de la Sierra Norte: el número de parados se reduce de 5.733 en 1986 a 3.042 en 1998). En el Corredor de la Plata (Cuadro $\mathrm{n}^{\circ}$ 17) los resultados se asemejan a los de la provincia entre 1991 y 1994: con un incremento del 7,07\% (recordemos que esta comarca no disfrutó del LEADER I); sin embargo, entre 1994 y 1998 (periodo en el que está en marcha el LEADER II) se recogen disminuciones en el paro muy superiores: un $37,45 \%$ frente al $21,31 \%$ que se produce como media en Sevilla.

\subsubsection{Mejora de calidad}

La calidad de vida del entorno social y urbano actúa como un factor creciente de atracción de la población. La aparición en las últimas décadas de nuevos medios avanzados de transportes y comunicaciones, así como la incidencia de las 
nuevas tecnologías están haciendo cada vez más fácil y posible la descentralización. De los indicadores sociales se intenta investigar la distribución y evolución en el tiempo del bienestar de la población, evaluando el avance o retroceso de la sociedad en la sanidad, educación y cultura.

\section{CUADRO № 14 \\ EVOLUCIÓN DEL PARO REGISTRADO EN LAS COMARCAS \\ LEADER SEVILLANAS \\ (valores absolutos y tasas de crecimiento)}

\begin{tabular}{lrrrrrrr}
\hline & 1986 & 1991 & 1994 & 1998 & $86-91$ & $91-94$ & $94-98$ \\
\hline Provincia Sevilla & 179.106 & 135.002 & 151.692 & 119.361 & $-24,62 \%$ & $12.36 \%$ & $-21.31 \%$ \\
Sierra Norte & 4.760 & 1.906 & 1.584 & 989 & $-59,96 \%$ & $-16.89 \%$ & $-37.56 \%$ \\
Sierra Sur & 5.733 & 3.646 & 3.228 & 3.042 & $-36.40 \%$ & $-11.46 \%$ & $-5.76 \%$ \\
Corredor de la Plata & 1.435 & 1.781 & 1.907 & 1.231 & $24,11 \%$ & $7,07 \%$ & $-35.45 \%$ \\
\hline
\end{tabular}

Fuente: INEM, Sevilla, varios años, en Anuarios Estadísticos de la Provincia de Sevilla (1992-1995). Diputación Provincial de Sevilla, Sevilla, varios años y Sistema de Información Multiterritorial de Andalucía (SIMA) 1999, Instituto Andaluz de Estadística, Junta de Andalucía y elaboración propia.

\section{CUADRO № 15}

EVOLUCIÓN DEL PARO REGISTRADO EN LA SIERRA NORTE (valores absolutos y tasas de incremento)

\begin{tabular}{lrrrrrrc}
\hline Municipios & 1986 & 1991 & 1994 & 1998 & $86-91$ & $91-94$ & $94-98$ \\
\hline Alanís & 341 & 187 & 131 & 64 & $-45,16 \%$ & $-29,95 \%$ & $-51,15 \%$ \\
Almadén de la Plata & 117 & 135 & 132 & 103 & $15.38 \%$ & $-2,22 \%$ & $-21.97 \%$ \\
Cazalla de la Sierra & 946 & 326 & 298 & 174 & $-65.54 \%$ & $-8,59 \%$ & $-41,61 \%$ \\
Constantina & 1327 & 497 & 375 & 262 & $-62.55 \%$ & $-24,55 \%$ & $-30.13 \%$ \\
Guadalcanal & 361 & 171 & 134 & 77 & $-52,63 \%$ & $-21,64 \%$ & $-42.54 \%$ \\
Las Navas & 656 & 88 & 71 & 34 & $-86,59 \%$ & $-19,32 \%$ & $-52,11 \%$ \\
El Pedroso & 324 & 113 & 144 & 92 & $-65,12 \%$ & $27,43 \%$ & $-36.11 \%$ \\
La Puebla de los Infantes & 470 & 228 & 134 & 82 & $-51,49 \%$ & $-41,23 \%$ & $-38,81 \%$ \\
El Real de la Jara & 125 & 94 & 101 & 72 & $-24,80 \%$ & $7,45 \%$ & $-28,71 \%$ \\
San Nicolás del Puerto & 93 & 67 & 64 & 29 & $-27,96 \%$ & $-4,48 \%$ & $-54,69 \%$ \\
\hline Sierra Norte & 4.760 & 1.906 & 1.584 & 989 & $-59,96 \%$ & $-16,89 \%$ & $-\mathbf{3 7 , 5 6 \%}$ \\
\hline Provincia Sevilla & 179.106 & 135.002 & 151.692 & 119.361 & $-24,62 \%$ & $12,36 \%$ & $-21,31 \%$ \\
\hline
\end{tabular}

Fuente: INEM, Sevilla, varios años, en Anuarios Estadísticos de la Provincia de Sevilla (1992-1995), Diputación Provincial de Sevilla, Sevilla, varios años y Sistema de Información Multiterritorial de Andalucía (SIMA) 1999, Instituto Andaluz de Estadística, Junta de Andalucía y elaboración propia. 


\section{CUADRO № 16}

EVOLUCIÓN DEL PARO REGISTRADO EN LA SIERRA SUR (valores absolutos y tasas de crecimiento)

\begin{tabular}{|c|c|c|c|c|c|c|c|}
\hline Municipios & 1986 & 1991 & 1994 & 1998 & $86-91$ & $91-94$ & $94-98$ \\
\hline Aguadulce & 229 & 95 & 74 & 60 & $-58,52 \%$ & $-22, \mathrm{I} 1 \%$ & $-18,92 \%$ \\
\hline Algámitas & 206 & 212 & 135 & 91 & $2,91 \%$ & $-36,32 \%$ & $-32,59 \%$ \\
\hline Badolatosa & 266 & 163 & 156 & 98 & $-38,72 \%$ & $-4,29 \%$ & $-37,18 \%$ \\
\hline Casariche & 391 & 195 & 240 & 214 & $-50,13 \%$ & $23,08 \%$ & $-10,83 \%$ \\
\hline Los Corrales & 494 & 288 & 190 & 120 & $-41,70 \%$ & $-34,03 \%$ & $-36,84 \%$ \\
\hline Estepa & 500 & 506 & 535 & 1197 & $1,20 \%$ & $5,73 \%$ & $123,74 \%$ \\
\hline Gilena & 418 & 149 & 150 & 110 & $-64,35 \%$ & $0,67 \%$ & $-26,67 \%$ \\
\hline Herrera & 414 & 296 & 348 & 306 & $-28,50 \%$ & $17,57 \%$ & $-12,07 \%$ \\
\hline Lora de Estepa & 157 & 42 & 41 & 28 & $-73,25 \%$ & $-2,38 \%$ & $-31,71 \%$ \\
\hline Marinaleda & 341 & 82 & 134 & 100 & $-75,95 \%$ & $63,41 \%$ & $-25,37 \%$ \\
\hline Martín de la Jara & 228 & 177 & 103 & 76 & $-22,37 \%$ & $-41,81 \%$ & $-26,21 \%$ \\
\hline Pedrera & 606 & 354 & 328 & 175 & $-41,58 \%$ & $-7,34 \%$ & $-46,65 \%$ \\
\hline La Roda de Andalucía & 376 & 270 & 267 & 164 & $-28,19 \%$ & $-1,11 \%$ & $-38,58 \%$ \\
\hline El Rubio & 409 & 185 & 146 & 76 & $-54,77 \%$ & $-21,08 \%$ & $-47,95 \%$ \\
\hline El Saucejo & 495 & 348 & 260 & 170 & $-29,70 \%$ & $-25,29 \%$ & $-34,62 \%$ \\
\hline Villanueva de San Juan & 203 & 284 & 121 & 57 & $39,90 \%$ & $-57,39 \%$ & $-52,89 \%$ \\
\hline Sierra Sur & 5.733 & 3.646 & 3.228 & 3.042 & $-36,40 \%$ & $-11,46 \%$ & $-5,76 \%$ \\
\hline Provincia Sevilla & 179.106 & 135.002 & 151.692 & 119.361 & $-24,62 \%$ & $12,36 \%$ & $-21,31 \%$ \\
\hline
\end{tabular}

Fuente: INEM, Sevilla, varios años, en Anuarios Estadísticos de la Provincia de Sevilla (1992-1995), Diputación Provincial de Sevilla, Sevilla, varios años y Sistema de Información Multiterritorial de Andalucía (SIMA) 1999, Instituto Andaluz de Estadística, Junta de Andalucía y elaboración propia.

Debemos recordar que la gran mayoría de las actuaciones en materias sanitarias o educativas se realizan independientemente de las iniciativas de desarrollo rural que se estén ejecutando en la zona. Así, la universalización de la sanidad y de la educación fueron dos procesos que culminaron con la democratización de España, se realizaron con anterioridad y de forma ajena a las iniciativas que estamos analizando; aunque su influencia en el desarrollo de las zonas rurales haya sido fundamental.

\section{A) Servicios educativos}

El nivel de los servicios educativos constituye uno de los principales indicadores sociales del desarrollo socioeconómico así como de sus posibilidades futuras en nuestra sociedad. 


\section{CUADRO № 17}

EVOLUCIÓN DEL PARO REGISTRADO EN EL CORREDOR DE LA PLATA (valores absolutos $\mathrm{y}$ tasas de crecimiento)

\begin{tabular}{lrrrrrrr}
\hline Municipios & 1986 & 1991 & 1994 & 1998 & $86-91$ & $91-94$ & $94-98$ \\
\hline Aznalcóllar & 301 & 320 & 407 & 260 & $6,31 \%$ & $27,19 \%$ & $-36,12 \%$ \\
Castilblanco & 295 & 266 & 380 & 223 & $-9,83 \%$ & $42,86 \%$ & $-41,32 \%$ \\
Castillo de las Guardas & 150 & 133 & 114 & 88 & $-11,33 \%$ & $-14,29 \%$ & $-22,81 \%$ \\
El Garrobo & 90 & 103 & 128 & 70 & $14,44 \%$ & $24,27 \%$ & $-45,31 \%$ \\
Gerena & 442 & 777 & 711 & 479 & $75,79 \%$ & $-8,49 \%$ & $-32,63 \%$ \\
El Madroño & 31 & 35 & 26 & 13 & $12,90 \%$ & $-25,71 \%$ & $-50,00 \%$ \\
El Ronquillo & 126 & 147 & 141 & 98 & $16,67 \%$ & $-4,08 \%$ & $-30,50 \%$ \\
\hline Corredor de la Plata & 1.435 & 1.781 & 1.907 & $\mathbf{1 . 2 3 1}$ & $\mathbf{2 4 , 1 1 \%}$ & $\mathbf{7 , 0 7 \%}$ & $\mathbf{- 3 5 , 4 5 \%}$ \\
\hline Provincia Sevilla & $\mathbf{1 7 9 . 1 0 6}$ & $\mathbf{1 3 5 . 0 0 2}$ & $\mathbf{1 5 1 . 6 9 2}$ & $\mathbf{1 1 9 . 3 6 1}$ & $\mathbf{- 2 4 , 6 2 \%}$ & $\mathbf{1 2 , 3 6 \%}$ & $\mathbf{- 2 1 , 3 1 \%}$ \\
\hline
\end{tabular}

Fuente: INEM, Sevilla, varios años, en Anuarios Estadísticos de la Provincia de Sevilla (1992-1995), Diputación Provincial de Sevilla, Sevilla, varios años y Sistema de Información Multiterritorial de Andalucía (SIMA) 1999, Instituto Andaluz de Estadística, Junta de Andalucía y elaboración propia.

Para este servicio se ha tomado la tasa de escolaridad por grupos de edad, y en la que se puede observar (Cuadro $\mathrm{n}^{2} 18$ ) como el carácter obligatorio de la Enseñanza Básica (6-13 años) se encuentra con una tasa muy próxima al $100 \%$. Por ello, el intervalo más representativo es el que corresponde a los alumnos que se encuentran cursando la Enseñanza Media (14-17 años) y la Enseñanza Superior (18-25 años). Dichas tasas de escolaridad han aumentado considerablemente respecto a 1981, principalmente en las Enseñanzas Medias, produciéndose un aumento considerado en las comarcas de la Sierra Norte $(9,64$ a $19,66 \%)$, Corredor de la Plata $(9,69$ a $18,1 \%)$. En cambio, en Estepa-Sierra Sur $(8,57$ a 14,2\%), no han crecido del todo por la necesidad de incorporar a los jóvenes al mercado de trabajo comarcal.

La formación es un aspecto esencial en los programas de desarrollo rural, pero debe planificarse, ya que hay que unirla siempre a un objetivo concreto, a un proyecto de desarrollo específico, en los que se analicen las características de los colectivos destinatarios, y se detecte las necesidades formativas, implicando a la población.

Desde la iniciativa comunitaria de Empleo y Desarrollo de los Recursos Humanos, se ha apoyado a las mujeres (NOW), grupos desfavorecidos (HORIZON) y jóvenes (YOUTHSTART) para que se enfrenten al mercado laboral. Igualmente, se ha establecido un marco de ayuda a los trabajadores industriales (ADAPT) dando prioridad a las acciones encaminadas a facilitar la adaptación de la mano de obra con mayor riesgo de desempleo. 
TASA DE ESCOLARIDAD POR GRUPOS DE EDAD

\begin{tabular}{lcccc}
\hline & $4-5$ años & $6-13$ años & $14-17$ años & $18-25$ años \\
\hline $\begin{array}{l}\text { Sierra Norte } \\
1981\end{array}$ & 73,69 & 97,68 & 44,51 & 9,64 \\
1991 & 91,96 & 99,31 & 67,35 & 19,66 \\
& & & & \\
Corredor de la Plata & & & & \\
$\quad 1981$ & 72,58 & 96,89 & 47,62 & 9,69 \\
1991 & 93,38 & 98,67 & 78,10 & 18,10 \\
& & & & \\
Estepa- Sierra Sur & & & & \\
1981 & 68,97 & 97,66 & 31,80 & 8,57 \\
1991 & 87,14 & 99,16 & 56,41 & 14,20 \\
\hline
\end{tabular}

Fuente: INE. Censo de Población 1981. IEA. Censo de Población de Andalucía. 1991. En SIMA 1999 Elaboración propia.

Finalmente, la iniciativa comunitaria LEADER recoge una medida de actuaciór específica dirigida a la formación «a la carta» en el medio rural. Las acciones formativas llevadas a cabo han permitido una mayor cualificación en el procesc de diversifícación económica en el medio rural, mediante la formación de colectivos específicos en materias que no contemplan los Programas de Formación (Formación Profesional reglada, Formación Ocupacional, Formación Continua, etc.', gestionada por distintas instituciones. Por ello, los inconvenientes y las ventajas que tienen los LEADER y PRODER para acceder a la fórmula de los programas de FORCEM, a continuación se describen (Esquema $n^{0} 2$ ), extraídos de las Jornadas Técnicas de la Unidad Española del Observatorio europeo Leader, celebradas en A Cañiza (Pontevedra).

Los programas realizados desde la iniciativa LEADER II en la provincia de Sevilla se han centrado principalmente en dotar a la población de las capacidades teóricas y técnicas necesarias para llevar a cabo las actividades prioritarias de cada comarca. Los cursos desarrollados más numerosos han estado referidos a las técnicas para la promoción de determinadas actividades turísticas (Corredor de la Plata), perfeccionamiento de idiomas en el sector turístico y monitor de turismc rural (Sierra Norte y Estepa-Sierra Sur). Así como los referidos al sector agroalimentario e industrial: cursos sobre el proceso industrial del corcho, apicultura, fabricación de quesos, gestores de empresas (Sierra Norte), recuperación de actividades tradicionales como la cestería, guamicionería, corcho, etc. (Sierra Norte y Estepa-Sierra Sur). 
ESQUEMA № 2

INCONVENIENTES Y VENTAJAS DE LOS PROGRAMAS COMUNITARIOS PARA ACCEDER A PROGRAMAS FORCEM

\section{Inconvenientes}

Las otras opciones formativas, cuando presentan una gama amplia y bien difundida financian el $100 \%$ de la acción, y en este sentido no se puede competir con ellas.

Existen problemas con la elegibilidad de determinadas acciones formativas.

\section{Ventajas}

El hecho de que las otras opciones formativas están diseñadas desde arriba, es frecuente su inadecuación a las necesidades reales del territorio.

La flexibilidad, la adaptación casi a la medida, con la posibilidad de atender a cualquier colectivo o contenido.

La necesidad de adecuar a un proceso largo, La agilidad y rapidez en la respuesta. como es un programa de desarrollo rural, acciones formativas temporales.

La posibilidad de abrir la asistencia a destinatarios de los grupos colindantes.

La organización de periodos de formación por intercambio o el uso de fórmulas como el viaje formativo.

Elaboración propia.

Poco a poco se van sentando las bases de formación con la puesta en marcha del Proyecto Formador (Corredor de la Plata), comenzando sus actuaciones a través de una serie de instrumentos ampliamente conocidos en materia de formación vinculados al desarrollo local: viveros de empresas, aulas permanentes de formación, programas de formación profesional ocupacional y escuela taller.

Y la mejora de los niveles de formación y capacitación empresarial, especialmente en el sector de las pymes (Estepa-Sierra Sur) han posibilitado la creación de un observatorio comarcal del mercado de trabajo, que entre sus diferentes funciones diseñará las necesidades de formación, cualificación o reciclaje que demanden las empresas.

Una de las facetas que más se ha puesto de manifiesto, a la hora de estudiar el estado de los recursos humanos y de la cualificación de la mano de obra, es el hecho de que la formación específica debe ir acompañada en todos los casos de una formación en temas de comercialización y distribución en los productos; así se estará contribuyendo a que se genere un mayor valor añadido a la que se va adquiriendo más independencia con respecto a otras áreas. 
B) Servicios sanitarios

En el equipamiento sanitario hemos considerado como variables los centro sanitarios, el personal sanitario y la densidad sanitaria. Los centros sanitarios, célul básica de la organización de los servicios sanitarios, son más numerosos en Este pa-Sierra Sur, que en el resto de comarcas LEADER II de la provincia de Sevilla La densidad sanitaria compuesto por el personal sanitario (médicos y pediatras) : su relación con la población de la comarca, para conocer el acceso a los servicio de salud, de nuevo nos da mejores resultados en Estepa-Sierra Sur, seguido de li Sierra Norte y del Corredor de la Plata.

CUADRO № 19

DISTRIBUCIÓN DE LOS SERVICIOS SANITARIOS. 1995

Centros Sanitarios Personal Sanitario Densidad Sanitaria

$\begin{array}{lrrr}\text { Sierra Norte } & 9 & 20 & 0,000583 \\ \text { Corredor de la Plata } & 6 & 8 & 0,000402 \\ \text { Estepa-Sierra Sur } & 21 & 57 & 0,000917\end{array}$

Fuente: Consejería de Asuntos Sociales, SAS. En SIMA 1999. Elaboración propia.

Desde la iniciativa LEADER y aunque en el caso de la provincia de Sevilla no se ha desarrollado ninguna actuación sanitaria; lo más frecuente es que se ha yan constituido algunos centros geriátricos con estas ayudas, debido al considera ble crecimiento que está experimentando la población superior a los 65 años

\section{C) Servicios culturales}

La variable menos cuantitativa es, sin duda, la de los servicios culturales, y er las que difícilmente estás intervienen en las actuaciones subvencionables por los programas de desarrollo. Por ello, y como representación de ellas, se encuentrar el número de bibliotecas públicas existentes en nuestro ámbito de estudio, las cuales no han sufrido transformaciones en el periodo entre 1993-1997, como se observi en el Cuadro n² 20.

En la iniciativa LEADER y desde el punto cultural, son numerosas las actuaciones que se están realizando para mejorar la calidad cultural de la población local Las exposiciones, ferias y encuentros culturales constituyen magníficos métodos de valorización e identificación comarcal, que contribuyen de forma decisiva a lé dinamización tanto social como económica de cada zona. 
CUADRO № 20

BIBLIOTECAS PÚBLICAS (1993-1997)

1993

1997

Sierra Norte

$\begin{array}{rr}4 & 6 \\ 2 & 2 \\ 14 & 12\end{array}$

Corredor de la Plata

Estepa-Sierra Sur

\section{2}

12

Fuente: SIMA 1999. Elaboración propia.

En cuanto a las intervenciones para la creación de equipamientos culturales se puede distinguir:

1. Instalaciones depositarias del patrimonio histórico, artístico y documental, principalmente museos etnográficos.

2. La difusión de la información de cada comarca a través de medios de comunicación locales: periódicos y revistas, publicaciones, emisoras locales.

3. La consolidación y rehabilitación de espacios aptos para uso natural y cultural: edificios emblemáticos, plazas, patios, jardines.

Desde las comarcas LEADER se han creado unos mínimos equipamientos recreativo-deportivo, basados en el aprovechamiento racional de los recursos naturales y socioculturales disponibles, que sean complementario tanto de la oferta existente como de nueva creación.

El Corredor de la Plata ha puesto en valor el paraje natural del pantano de Aznalcóllar, así como la restauración del castillo del Castillo de las Guardas. Y la Sierra Norte tiene previsto la creación del Centro de Interpretación de la Dehesa; en cambio Estepa-Sierra Sur está creando zonas deportivas/piscinas, picaderos, escuela de caza, etc.

\section{CONCLUSIONES}

La mayoría de las zonas rurales de la Unión Europea han estado afectada por importantes evoluciones que durante decenios han proporcionado al mundo rural una imagen que ha disminuido su capacidad de atracción: declive del empleo y de la actividad agrícola, éxodo de los jóvenes mejor formados, aumento del desempleo rural y del número de personas en situación de empleo precario, aislamiento ante la desaparición de ciertos servicios, daños causados al medio ambiente, etc. Pero son muchos los cambios que se han producido en las comarcas rurales durante la década de los 90 . Se ha pasado del proteccionismo a la competitividad, 
de la homogeneidad productiva a la diversidad, especialización y profesio. nalización. Se han puesto en uso recursos que han permanecido tradicionalment $\epsilon$ infrautilizados mediante la valorización del patrimonio natural y cultural. Del éxodc rural se ha pasado a la movilización del potencial humano. En muchas comunidades locales, la iniciativa comunitaria LEADER ha sido la base para crear una identidad comarcal, anteriormente inexistente.

Debemos recordar que esta iniciativa comunitaria no es un programa asistencial basado en una proporcionalidad para distribuir fondos públicos de forma lineal entre los municipios. Tampoco el objeto es mejorar las infraestructuras y equipamientos públicos básicos, ya que existen otras fuentes mucho más específicas. Este programa no se basa en la animación sociocultural ni está dirigido a proteger exclusivamente los recursos naturales y culturales para asegurar el recreo y ocio de los visitantes.

Por encima de cualquier aportación, los programas LEADER y PRODER han puesto en práctica el más auténtico concepto y proceso de desarrollo rural y han demostrado, con realidades, la eficacia de un sistema que se aleja de los sistemas tradiciouales de actuación con la población local.

Estos programas han permitido desarrollar numerosas actuaciones en el medio rural, aunque otras no han conseguido llegar a lo óptimo que se esperaba, tanto por las inversiones empresariales, la acción pública o por motivos estructurales.

La participación social, el tejido asociativo, la gestión e integración de otros programas en las comarcas, el papel de la administración local y de la iniciativa privada son algunos de los logros que se han conseguido con este programa comunitario.

\section{1. ¿Se ha mantenido a la población rural?}

Las tendencias y procesos que han caracterizado la demografía han cambiado. Si bicn es cierto que algunas zonas han perdido mucha población, otras están empezando a recuperarse, tras la crisis demográfica que caracterizó a las poblaciones rurales a finales de $\operatorname{los} 80$.

Los efectos negativos que sobre la estructura demográfica tiene el envejecimiento del medio rural al expulsar a los jóvenes, puede paliarse en la medida que la diversificación de actividades permita un menor desarraigo de la población joven; y con ello, se podrá en un futuro compensar el desequilibrio actual. Estas comarcas LEADER siguen teniendo más envejecimiento que la media de la provincia de Sevilla, aunque la tendencia se suaviza.

El secular proceso de despoblamiento nural parece haber tocado fondo. Se aventura incluso el inicio de una nueva fase de reacción que consistirá en el repoblamiento rural, producido por la vuelta de población retirada y segundos residentes. 


\section{2. ¿De qué manera se ha revitalizado el tejido socioeconómico?}

La diversificación de las actividades económicas en el ámbito rural se ha convertido en una necesidad para la adaptación e integración de las zonas rurales en el sistema de producción del que han estado históricamente marginadas. Por lo que ha sido preciso estimular un cambio en la distribución de rentas, equilibrando la estructura económica. Lo realmente duro, ha sido redefinir las funciones de la población en los espacios rurales desde escalas supranacionales, ante la incomprensión de los cambios de los hábitos de vida.

En relación a la evolución de la renta en las comarcas LEADER I analizadas podemos afirmar que se produce una mejora en la distribución espacial de la misma en un doble sentido. De un lado, acercan su renta a la media provincial puesto que experimentan incrementos muy superiores. De otro, se reducen las diferencias entre los municipios de cada comarca, pues las subidas mayores se producen en los más pobres; aún así la renta sigue siendo superior en las zonas donde se concentra la actividad empresarial.

En el intento por diversificar la economía de las zonas rurales, se insertan las pequeñas y medianas empresas que han proliferando bajo el fenómeno del asociacionismo. Dicho movimiento ha sido una aportación esencial en la búsqueda y puesta en marcha de soluciones para el desarrollo de las comarcas rurales, contribuyendo a consolidar el proceso de transformación política y económica. EI asociacionismo en el medio rural se ha mostrado como el principal instrumento para la mejora de las rentas, para la fijación del valor añadido en el medio rural, para la adopción y desarrollo de las innovaciones tecnológicas.

El desarrollo rural ha ayudado a la diversificación de las actividades económicas: creando empleo y, en especial, autoempleo; apoyando la mejora de la calidad de los productos, aunque no del todo su comercialización; potenciando el uso ordenado del patrimonio y valorizando las tradiciones de cada comarca.

3. ¿Se ha creado entpleo?

Las conclusiones para el mercado de trabajo son muy similares a las obtenidas con relación a la renta:

- Entre 1991 y 1994 (LEADER I) las tasas de paro de los municipios de la Sierra Norte y de Estepa-Sierra Sur se reducen, mientras que en Sevilla y en el Corredor de la Plata se están incrementando; por lo tanto, la situación relativa de estas comarcas mejora. Los municipios con mayores tasas de desempleo son los que experimentan reducciones más importantes, lo que conduce a un reparto más equitativo de los frutos del crecimiento. 
- Entre 1994 y 1998 (LEADER II) observamos como también el Corredor d la Plata mejora su posición respecto a Sevilla en cuanto a paro registrado

Por lo tanto, podemos afirmar que los LEADER han contribuido al logro di su objetivo de incrementar la renta, mejorar su distribución y crear empleo. Tant en mercado de trabajo como en renta, los resultados (como media) de la Sierr: Norte son superiores a los de la Sierra Sur, lo que se debe a la mayor homogenei dad existente entre sus municipios, ya que en Estepa-Sierra Sur al ser tantos y tat diversos, las medias son menos representativas.

De la misma manera que hay que reconocer la importancia de la formación también hay que decir que ésta no siempre se ha orientado adecuadamente, ni h: respondido siempre a las necesidades claras de las comunidades locales, ambo: motivos pueden que hayan sido decisivos por lo que la formación en los progra mas LEADER no ha tenido los resultados que se esperaban. Las accione: formativas en el desarrollo rural no han respondido a las realidades, no se har planteado adecuadamente, y su impacto no es el esperado. Por ello, algunas cues. tiones básicas que se han de tener en cuenta es que la formación es un proceso dt conocimiento, y no un producto alternativo.

La oferta pública formativa es amplia y variada; con ella se ha conseguido in. sertar a jóvenes de primer empleo gracias a las Escuelas Taller y Casas de Oficios como instrumentos que están favoreciendo la cualificación de amplios colectivos, proporcionando una formación especializada, adaptada a las necesidades de: área y sirviendo para proporcionar nuevas oportunidades a los jóvenes, favoreciendo el autoempleo y frenando la emigración de la población joven; ampliar la formación de los agricultores a través de las Organizaciones Profesionales Agrarias (OPAs); adaptar la oferta y demanda del mercado de trabajo por los programas FORCEM; todas ellas para mejorar la cualificación profesional.

\section{4. ¿Existe una mayor ordenación y protección del territorio?}

Desde esta iniciativa, en numerosas zonas se ha logrado que la población se reconozca con su comarca, desarrollando la unidad territorial mediante la identidad comarcal, la cual ha sido más fácil en aquellos grupos donde existían unos elementos naturales o históricos de nexo, que en aquellas que se constituyeron como meras comarcas funcionales. La articulación social del territorio y/o el reforzamiento de la identidad territorial es posible haciendo participe a la población local en la toma de decisiones y en la toma de conciencia de que la imagen de cada territorio es fruto y está vinculada al entomo, su historia o a los productos endógenos. Lo que está claro es que lograr que la población se sienta implicada en un proceso local de desarrollo supone confiar en ella, alentándola a decidir por sí misma. 
El LEADER ha ofrecido a la población local y a los agentes sociales y económicos, una buena oportunidad para el diseño y aplicación de un programa de desarrollo basado en una estrategia propuesta por ellos mismos a través de sus Grupos de Acción Local (GAL). Sobre todo cuando se ha propiciado la participación desde los primeros momentos como herramienta para mejorar la definición y ejecución de los programas.

El desarrollo rural está estrechamente condicionado a una planificación del territorio, pero éste siempre pasa a un segundo plano frente a las sucesivas leyes sobre el suelo que se vienen elaborando desde la única perspectiva de la urbanización. En la práctica, ello se traduce en consecuencias negativas para el desarro1lo, por la falta de inversiones en infraestructuras y mantenimiento.

Desde el punto de vista de la protección del medio rural, son muchos los problemas ambientales derivados de las actividades realizadas en cada comarca; de las infraestructuras que en ella se ubican; los problemas, ya sean estos urbanísticos, arquitectónicos, o de ocupación del suelo derivado de la aparición de nuevas construcciones; del consumo de energía y agua; del tratamiento de los residuos que se producen; o de la existencia de especies animales o vegetales, o de espacios y paisajes singulares, en situación delicada. Con el programa LEADER se ha abierto un amplio abanico de posibilidades de actuación, centradas principalmente en la información, sensibilización y concienciación ambiental, por lo que se han hecho mayoritariamente inventarios de los recursos existentes.

En definitiva, los LEADER han supuesto un cambio en la mentalidad tanto en los responsables políticos como en los agentes económicos y sociales que integran el mundo rural. La traducción de esta nueva filosofía a la realidad económica (y estadística) actual aún es escasa; no obstante, gran parte de las tendencias recesivas de décadas anteriores están comenzando a remitir. Por ello, todavía debemos esperar unos años para constatar la repercusión total de estas políticas en el mundo rural.

\section{BIBLIOGRAFÍA}

CALS, J. (1995): El turismo en el desarrollo rural de España. M.A.P.A. Madrid.

CALATRAVA REQUENA, J. (1993): «Los objetivos en Ios procesos de desarrollo rural» El desarrollo rural a las puertas del siglo XXI. Consejería de Agricultura y Pesca. Sevilla, pp. 85-96.

CEÑA DELGADO, F. (1993): «El desarrollo rural en sentido amplio». El desarrollo rural a las puertas del siglo XXI. Consejería de Agricultura y Pesca. Sevilla, pp. 27-39.

CORTÉS MACÍAS, R. (1996): «Iniciativas comunitarias de desarrollo rural en Andalucía».VII Coloquio de Geografia Rural. Universidad de Zaragoza y Asociación de Geógrafos Españoles, pp. $45-52$.

DIPUTACIÓN PROVINCIAL DE SEVILLA (varios años): Anuarins Estadísticos de la Provincia de Sevilla (1992-1995). Sevilla. 
FORONDA ROBLES, C. (1998): Oportunidades y desafios de las actividades emergentes. El turismo en la provincia de Sevilla. Colección Documentos $n^{\circ} 2$. Patronato provincial de Sevilla. Universidad de Sevilla.

IEA (1999): Sistema de Información Multiterritorial de Andalucía (SIMA) 1999, Sevilla, Junta de Andalucía.

JAZRA BANDARRA, N. (1995): «Las orientaciones recientes de la política agraria en la Unión Europea». Hacia un nuevo sistema rural. Serie Estudios. M.A.P.A. Madrid, pp. 133-149.

JUNTA DE ANDALUCÍA (1997): Guía de Desarrollo Rural. Consejería de Agricultura y Pesca.

MARQUEZ, D.; FORONDA, C.; GARCÍA, A. (1999): «Las zonas agrarias intermedias ante el desafío de la Agenda 2000» en RAMOS LEAL, E. (coord.) El desarrollo rural en la Agenda 2000. Ministerio de Agricultura y Pesca. Cap. 18, pp. 393-406.

MARTÍN MARTÍN, V. (1996): «La Geografía, la Unión Europea y el Desarrollo rural» VII Coloquio de Geografía Rural. Universidad de Zaragoza y Asociación de Geógrafos Españoles, pp. 237-249.

MELLA MÁRQUEZ, J.M. (1998): «Las encrucijadas de la economía andaluza» Economía y política regional en España ante la Europa del siglo XXI. Akal Textos. Madrid, pp. 306324.

MOLINA IBÁÑEZ, M. \& RODRÍGUEZ POSE, A. (1992): «Transformaciones agrarias en la Europa Comunitaria: efectos de la PAC». El medio rural español. Cultura, paisaje y naturaleza. M.A.P.A. Salamanca, pp. 699-706

MORENO BENITO, P. (1996): «Disposiciones planteadas para el desarrollo rural en las zonas de montaña» VII Coloquio de Geografía Rural. Universidad de Zaragoza y Asociación de Geógrafos Españoles, pp. 265-275.

PÉREZ YRUELA, M.; GIMÉNEZ GUERRERRO, M. (1995): «Desarrollo local y desarrollo rural: El contexto del programa LEADER».

REQUENA SÁNCHEZ, M.D. (1996): «Bases comunitarias para el desarrollo rural en zonas de montaña». VII Coloquio de Geografía Rural. Universidad de Zaragoza y Asociación de Geógrafos Españoles, pp. 339-347.

TIO SARALEGUI, C. (1995): «Implicaciones de la nueva política agraria internacional para el sistema agrario español». Hacia un nuevo sistema rural. Serie Estudios. M.A.P.A. Madrid, pp. 157-202. 